\title{
CHEST Diffuse granulomatous disease: looking inside and CLINIC outside the lungs
}

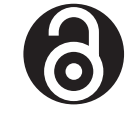

\section{OPEN ACCESS}

${ }^{1}$ Interstitial Lung Disease, Royal Brompton and Harefield NHS Foundation Trust, London, UK ${ }^{2}$ Immunology, Imperial College NHS Trust, London, UK ${ }^{3}$ Department of Histopathology, Royal Brompton and Harefield NHS Foundation Trust, London, UK

${ }^{4}$ Department of Radiology, Royal Brompton and Harefield NHS Foundation Trust, London, UK ${ }^{5}$ Moorfields Eye Hospital NHS Foundation Trust, London, UK

\section{Correspondence to}

Dr Alan Williams, Interstitial Lung Disease, Royal Brompton Hospital, London SW3 6NP, UK; alanw@doctors.org.uk

AW and FC are joint first authors.

Received 31 July 2019 Revised 18 October 2019 Accepted 18 October 2019 Published Online First 6 January 2020

Check for updates

(C) Author(s) (or their employer(s)) 2020. Re-use permitted under CC BY-NC. No commercial re-use. See rights and permissions. Published by BMJ.

To cite: Williams A, Kelleher WP, Nicholson AG, et al. Thorax

2020;75:189-191.

\author{
Alan Williams, ${ }^{1}$ W Peter Kelleher, ${ }^{2}$ Andrew G Nicholson, ${ }^{3}$ Anand Devaraj, ${ }_{1}^{4}$ \\ Carlos Pavesio, ${ }^{5}$ Felix Chua ${ }^{1}$
}

\section{DR ALAN WILLIAMS}

A 39-year-old woman presented with a 6-month history of breathlessness, productive cough and painful lumps on her lower legs. She had suffered with recurrent rhinosinusitis and frequent infections of the ears, throat and chest since childhood, as well as cutaneous herpes zoster in her 20s. There was no documented history of pneumonia, invasive or deep-seated infections. She had smoked lightly, was allergic to penicillin and worked as a commercial tea buyer.

Examination showed a slim female with a normal breathing pattern. Chest expansion was reduced and fine inspiratory crackles were detected over the lower lung zones. Pulmonary function tests showed ventilatory restriction with decreased gas transfer. Forced expiratory volume in one second $\left(\mathrm{FEV}_{1}\right)$ $2.10 \mathrm{~L}, 71 \%$ predicted; forced vital capacity (FVC) $2.22 \mathrm{~L}, 65 \%$ predicted; spirometric ratio 0.93 ; total lung capacity $3.04 \mathrm{~L}, 62 \%$ predicted; haemoglobin (Hb)-adjusted carbon monoxide transfer factor/ TLco $45 \%$ predicted and its coefficient/Kco $81 \%$ predicted. Indices related to small airway function were normal, maximal expiratory flow $(\mathrm{MEF})_{75 / 50 / 25}$ all above $80 \%$ predicted and air-trapping was absent.

Bloods tests showed normal full blood count, C-reactive protein as well as kidney, bone and liver biochemistry. Serum ACE was elevated at 93 ACEU (ref: 12-68). Elispot assay and HIV serology were negative.

\section{DR FELIX CHUA}

A prereferral chest radiograph revealed widening of the superior mediastinum and ill-defined nodular opacities in the middle and lower zones. Despite the history of possible erythema nodosum and raised serum ACE, the account of recurrent infections suggested a differential diagnosis broader than typical sarcoidosis. Demonstration of ventilatory restriction and impaired gas transfer factor hinted towards an interstitial or diffuse lung pathology. The $\mathrm{KcO}$, at nearly twice the TLco in \%-predicted terms, indicated a low likelihood of major pulmonary vasculopathy and the absence of airflow limitation or small airway dysfunction steered the diagnosis away from primary bronchiolar disorders. CT with contiguous image acquisition was undertaken.

\section{DR ANAND DEVARAJ}

CT of the thorax at presentation showed widely distributed bronchocentric nodules, some which were solid but others appearing cavitated (figure 1A). The possibility of pulmonary metastases of squamous cell origin was considered; however, the 'cavitation' in this case was artefactual and resulted from the presence of innumerable tiny nodules surrounding peripheral airways. Such appearances can occur in lymphocytic disorders (including lymphocytic interstitial pneumonia (LIP), follicular bronchiolitis and granulomatous lymphocytic interstitial lung disease (GLILD)), pulmonary Langerhans cell histiocytosis and pulmonary meningothelial-like nodules. Mediastinal lymphadenopathy and splenomegaly were also evident.

\section{DR FELIX CHUA}

Analysis of serum immunoglobulins revealed a suppressed profile: $\operatorname{IgG} 1.0 \mathrm{~g} / \mathrm{L}$ (ref: 6.4-16.0), IgA $<0.1 \mathrm{~g} / \mathrm{L}$ (ref: $0.7-3.2$ ), IgM $0.5 \mathrm{~g} / \mathrm{L}$ (ref: $0.5-2.8$ ). Pneumococcal IgG whole antibody titre $(<3.3 \mu \mathrm{g} /$ $\mathrm{mL}$, ref: $>20)$ and tetanus toxoid IgG whole antibody titre $(0.1 \mathrm{IU} / \mathrm{mL}$, ref: protective $\geq 0.15 \mathrm{IU} /$ $\mathrm{mL}$ ) were also reduced suggesting impaired $\mathrm{T}$ and
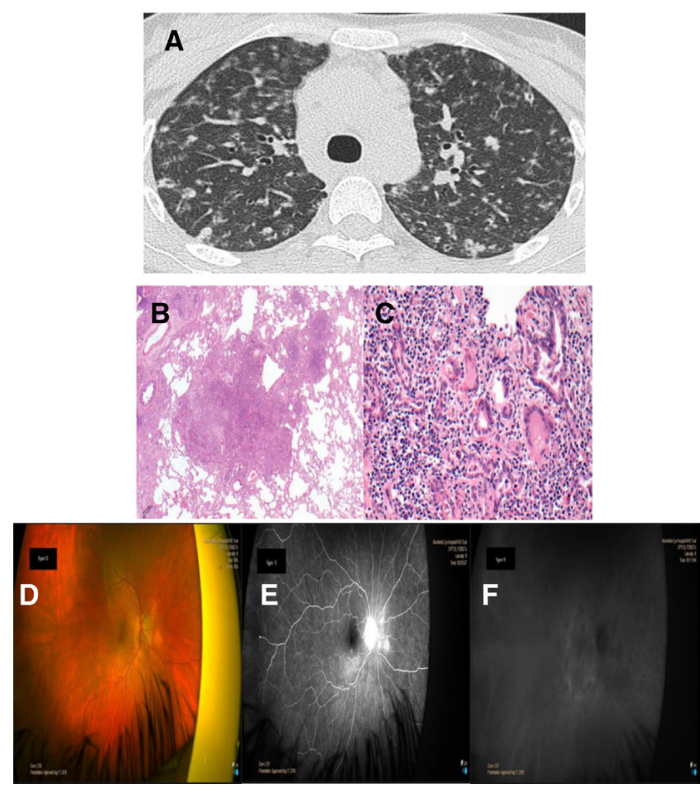

Figure 1 (A) Axial image of thoracic CT: bronchocentric nodules, some with apparent cavitation. (B) Mediumpower micrograph of predominantly lymphoid bronchocentric nodule, (C) H\&E-stained high-power micrograph of a non-necrotising granuloma, and ocular abnormalities demonstrated by (D) colour funduscopy, (E) fluorescein angiography and (F) idocyanine green angiography as described in the text. 
B cell-dependent antibody responses. T cell counts (CD3, CD4 and CD8) were normal; however, $B$ and natural killer (NK) cell numbers were reduced. Analysis of B lymphocyte subsets showed absent class-switched memory B, normal IgM memory and transitional B cell proportions. Naïve and memory CD4 and CD8 $\mathrm{T}$ cell percentages were also normal.

A working diagnosis of common variable immunodeficiency (CVID) was made, with differential diagnoses of sarcoidosis, atypical pulmonary infection and lymphoproliferative disease. Following discussion, the patient consented for video-assisted thoracoscopic lung biopsy.

\section{PROFESSOR ANDREW NICHOLSON}

Biopsies from two sites showed architecturally normal lung with numerous ill-defined, often bronchocentric nodules comprising a dense lymphoid infiltrate of small round lymphocytes without atypia. Intermixed were scattered blast-like cells, plasma cells, histiocytes and a few eosinophils (Figure 1B). There were scattered non-necrotising granulomas (figure 1C) and a localised nodule of necrosis surrounded by a rim of fibrosis and palisading granulomatous inflammation. Special stains for acid-fast bacilli (Ziehl Neelsen) and fungi (Grocott) were negative and immunohistochemistry showed no evidence of lymphoma.

\section{DR PETER KELLEHER}

The history of recurrent infections, marked reduction in immunoglobulin isotypes and specific antibodies (despite a history of recent tetanus vaccination), radiological and biopsy findings were highly suggestive of GLILD-CVID. Treatment comprising intravenous immunoglobulin (IVIG) replacement therapy every 3 weeks, regular sinus rinse and flixonase nasal spray was commenced.

\section{DR FELIX CHUA}

The patient did not return for respiratory monitoring for 3 years following her initial assessment. Regular IVIG replacement had resulted in significant and sustained symptomatic improvement and a decreased frequency of infections.

\section{DR PETER KELLEHER}

Corticosteroids were deferred in favour of close monitoring. The lumps on the patient's shins did not recur and she did not develop other extrapulmonary manifestations of CVID. Just before Christmas 2016, she completed a 24-mile mountain hike but noticed being slower than her companions. In spring 2017, her IVIG treatment was switched to subcutaneous IgG. Despite achieving comparable levels of circulating IgG, her original symptoms recrudesced, with additional abdominal pain and diarrhoea. Subclinical hypothyroidism and vitamin D deficiency were detected. Her thyroid function was monitored and high-dose vitamin $\mathrm{D}_{3}$ administered. Colonoscopy revealed focal dysplasia without colitis, a glucose breath test was normal and a 23-seleno-25 homotaurocholic acid (SeHCAT) radionuclide scan demonstrated moderate bile salt malabsorption. Next-generation sequencing for CVID-associated genes showed no pathogenic variants associated with GLILD. Reinstatement of IVIG replacement therapy led to prompt symptomatic improvement including resolution of breathlessness.

\section{DR FELIX CHUA}

At that point, a repeat HRCT undertaken approximately 3 years after the initial study demonstrated slightly increased numbers of bronchocentric nodules with stable appearances of lymph-

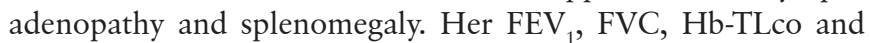
$\mathrm{Hb}-\mathrm{Kco}$ had not changed over the same interval.

\section{MR CARLOS PAVESIO}

Five months after restarting IVIG, the patient presented with a 6-day history of blurred vision in her right eye. Examination showed normal visual acuity, colour vision, pupillary reflexes, anterior segment and vitreous. However, funduscopy revealed a swollen right optic disc and an elevated subretinal lesion just inside the inferotemporal arcade as well as two smaller lesions nasal to the optic disc (figure 1D). Examination of the left eye was unremarkable.

Fluorescein angiography demonstrated a 'hot' right optic disc with a small area of retinal pigment epithelium (RPE) change in the inferior macula (figure 1E). No signs of vasculitis or macular oedema were detected. Indocyanine green angiography revealed the presence of hypofluorescent choroidal lesions in the central macula and the nasal peripapillary area which involved larger areas of the choroid than clinically suspected (figure $1 \mathrm{~F}$ ).

In the context of her clinical history, the choroidal abnormalities were highly indicative of granulomatous reactions commensurate with sarcoidosis or a sarcoid-like phenomenon. Treatment with high-dose prednisolone and acyclovir induced a dramatic response in the subretinal lesions. The optic disc swelling resolved after 6 weeks of treatment, allowing the steroid dose to be steadily tapered. At subsequent review, the only residual abnormalities were pigmentary changes of the RPE.

\section{DISCUSSION}

\section{Dr Felix Chua and Dr Peter Kelleher}

Common variable immune deficiency is the most common form of primary antibody deficiency in adults. It is characterised by defective antibody production and manifests as an increased susceptibility to infection, autoimmune disease, inflammatory disorders and lymphoma. Lymphadenopathy, splenomegaly and granulomatous involvement of the lungs and other viscera are described in 8\%-22\% of CVID patients. ${ }^{1}$ Pulmonary GLILD can be defined as 'a distinct clinico-radio-pathological ILD occurring in patients with CVID, associated with a lymphocytic infiltrate and/or granuloma in the respiratory system and in whom other conditions have been considered and where possible excluded'. Clinical features of GLILD may be non-specific but frequently include cough and progressive breathlessness. Key findings on lung biopsy include granulomatous inflammation, follicular bronchiolitis and LIP. Organising pneumonia and interstitial fibrosis are occasionally encountered.

The prognosis of GLILD-CVID is worse than 'infection only' variants of CVID due to the potential for developing respiratory failure. ${ }^{2}$ Ocular disease in CVID, while rare, includes granulomatous anterior and posterior uveitis, multifocal choroiditis (including Birdshot retinochoroidopathy) and retinal vasculitis. ${ }^{3}$ Distinguishing between sarcoidosis and GLILD can be difficult-a history of recurrent infections, autoimmune cytopaenia, decreased serum immunoglobulins and class-switched memory B cells as well as histopathological evidence of follicular bronchiolitis or LIP are indicative of GLILD.

Although immunoglobulin replacement can significantly reduce the frequency of severe pulmonary infections in CVID, it does not induce GLILD remission, prevent its progression or reduce mortality. There are currently no formal guidelines for the treatment of GLILD but expert opinion suggests that restoration of IgG levels is a vital initial step in its management, followed by 
corticosteroid therapy for symptomatic disease and/or deteriorating or abnormal lung function. There is little agreement on the choice of second-line agents but azathioprine, rituximab or mycophenolate mofetil have been used. In a very small cohort of patients, combined azathioprine-rituximab treatment was associated with improved lung function and radiological appearances. ${ }^{4}$ Antimicrobial prophylaxis is usually reserved for cases with recurrent infection. Improved understanding of monogenic causes of CVID will hopefully inform future advances in diseasetargeting therapies. ${ }^{5}$

The current case highlights two important aspects of GLILDCVID; first, its systemic nature and second, the fact that disease activity can variably manifest in different organ systems even in those receiving immunoglobulin replacement. In this particular case, ocular disease developed despite treatment-controlled pulmonary GLILD.

Funding The authors have not declared a specific grant for this research from any funding agency in the public, commercial or not-for-profit sectors.

Competing interests None declared.

Patient consent for publication Obtained.
Provenance and peer review Not commissioned; externally peer reviewed.

Open access This is an open access article distributed in accordance with the Creative Commons Attribution Non Commercial (CC BY-NC 4.0) license, which permits others to distribute, remix, adapt, build upon this work non-commercially, and license their derivative works on different terms, provided the original work is properly cited, appropriate credit is given, any changes made indicated, and the use is non-commercial. See: http://creativecommons.org/licenses/by-nc/4.0/.

\section{REFERENCES}

1 Hurst JR, Verma N, Lowe D, et al. British lung Foundation/United Kingdom primary immunodeficiency network consensus statement on the definition, diagnosis, and management of Granulomatous-Lymphocytic interstitial lung disease in common variable immunodeficiency disorders. J Allergy Clin Immunol Pract 2017;5:938-45.

2 Bates CA, Ellison MC, Lynch DA, et al. Granulomatous-lymphocytic lung disease shortens survival in common variable immunodeficiency. J Allergy Clin Immunol 2004;114:415-21.

3 Kashani S, Gazzard G, Jolles S, et al. Asymptomatic choroidal granulomas in common variable immunodeficiency. Clin Exp Ophthalmol 2005;33:663-4.

4 Maglione PJ, Overbey JR, Cunningham-Rundles C. Progression of common variable immunodeficiency interstitial lung disease accompanies distinct pulmonary and laboratory findings. J Allergy Clin Immunol 2015;3:941-50.

5 Chase NM, Verbsky JW, Hintermeyer MK, et al. Use of combination chemotherapy for treatment of granulomatous and lymphocytic interstitial lung disease (GLILD) in patients with common variable immunodeficiency (CVID). J Clin Immunol 2013;33:30-9. 